\title{
dossier
}

\section{Toribio de Mogrovejo, Roma y la creación de un esquema de gobierno diocesano en Sudamérica}

\author{
Constanza López LAMERAIN \\ Universidad de Chile (Santiago, Chile) \\ mconstanza.lopezlamerain@gmail.com \\ Código ORCID: 0000-0002-1689-0912
}

\section{RESUMEN}

En el siglo XVI, desde el arzobispado de Lima comenzó a crearse un estilo de gobierno eclesiástico metropolitano que brindara un claro camino a seguir a las nacientes diócesis de la provincia eclesiástica del Perú. En parte esto fue modelándose a partir de los concilios provinciales celebrados en la Ciudad de los Reyes, y más aún luego de la recepción del Concilio de Trento. Con Toribio de Mogrovejo a la cabeza del arzobispado de Lima, se reforzaron las estructuras eclesiásticas bajo el liderazgo de los obispos, figuras claves de la reforma tridentina y el gobierno de la Iglesia Universal. Mogrovejo siguió pormenorizadamente los lineamientos del tridentino, lo que queda manifiesto por la fluida comunicación que durante su gobierno mantuvo con la Santa Sede, presentando 
informaciones y dudas de aplicación de derecho canónico para su provincia con el fin de reforzar su gobierno metropolitano y su jurisdicción episcopal.

Palabras Clave: arzobispo de Lima, gobierno metropolitano, Santa Sede, jurisdicción episcopal, reforma tridentina, derecho canónico

\title{
Toribio de Mogrovejo, Rome, and the creation of a diocesan govern- ment model in South America
}

\begin{abstract}
In the 16th century, from the Archbishopric of Lima, a metropolitan governance model was being conceived as a path to be followed by the young dioceses of the ecclesiastical province of Peru. For this matter, the celebration of provincial councils in Lima was fundamental, even more after the council of Trent. With Toribio de Mogrovejo at the head of the archdiocese of Lima, the ecclesiastical structures were reinforced under the leadership of the bishops, key figures of the Tridentine reform and the government of the Universal Church. Mogrovejo followed the Tridentine's guidelines in detail, which is evidenced by the fluid communication he maintained with the Holy See, presenting information and doubts about the application of canon law for his province in order to strengthen his episcopal jurisdiction and local influence.
\end{abstract}

KeYwords: Archbishop of Lima, metropolitan governance, Holy See, episcopal jurisdiction, Tridentine reform, canon law 


\section{INTRODUCCIÓN}

El PRESENTE ARTículo ARgUMENTA QUE, durante el proceso de construcción de la Iglesia diocesana en América del Sur, la recepción ${ }^{1}$ de los decretos del Concilio de Trento (1545-1563) presentó una oportunidad para que los arzobispos de Lima fortalecieran su autoridad y consolidaran su gobierno a nivel metropolitano. La incorporación de la reforma tridentina en los espacios locales no solamente generó una nueva normativa canónica para la región, sino que también abrió una puerta a las comunicaciones entre las iglesias locales y la Santa Sede. Aunque, como es sabido, estas ya existían con anterioridad, es posible interpretar la reforma universal inaugurada por Trento como una apertura en estas comunicaciones, ya que, desde el punto de vista del papado, la premura de su aplicación renovaba el vínculo entre el gobierno central y los gobiernos locales. Por su parte, la Corona española contaba con la responsabilidad de aplicar la reforma tridentina en todos sus dominios, acción que le sirvió también para ejercer control sobre las estructuras eclesiásticas en sus territorios, influyendo directamente en la organización de la Iglesia americana a través del Patronato regio. En el caso de los obispos sufragáneos, la preminencia que Trento dio a los obispos en la ejecución de la reforma les permitió afianzar su posición frente a otras figuras que disputaban su poder a nivel local — tanto eclesiásticas como seglares-, brindándoles un mayor rango de acción en sus contextos.

1 Se han utilizado genéricamente las palabras «recepción» y «aplicación» para describir la incorporación de la reforma tridentina en las iglesias locales, especialmente mediante la celebración de concilios provinciales y sínodos diocesanos, instancias de creación de una normativa congruente a los preceptos del Concilio de Trento. No obstante, estos términos han probado ser insuficientes para explicar un fenómeno más amplio y que no es unidireccional. Se ha incorporado el uso de palabras alternativas como «traducciones» $\mathrm{o}$ «transferencias», que incorporarían otras formas de impacto de la reforma en el ámbito local. Sobre el término de traducción en este sentido he profundizado en López Lamerain (2018, pp. 47-48). 
Los concilios provinciales que fueron llamados a convocarse al cierre del ecuménico han sido considerados espacios en que la normativa tridentina se introdujo y adaptó en las iglesias locales. ${ }^{2}$ Es innegable que estas reuniones fueron esenciales para tal objetivo; sin embargo, no fueron las únicas instancias de aplicación de la reforma en la regulación de las diócesis.

Mi planteamiento es que los concilios provinciales, además de incorporar las directrices del ecuménico, crearon una coyuntura que los obispos y otros actores de la naciente Iglesia en el virreinato peruano utilizaron para establecer comunicaciones con la Santa Sede, presentando sus dificultades ante las instituciones romanas. Así, produjeron una instancia que, aunque no fue ni novedosa ni poco común ya que era un recurso siempre abierto en la tradición católica, sentó un precedente que en el caso de la provincia peruana fue utilizado para plantear temas de gobierno diocesano ante instancias romanas, a pesar de las restricciones impuestas por el Patronato regio. Me centraré aquí solo en algunas de las comunicaciones que el segundo arzobispo de Lima, Toribio de Mogrovejo (1579-1606), envió a Roma con este fin, aunque ya su antecesor, Jerónimo de Loaysa, había hecho lo propio en el contexto del segundo concilio provincial. Propongo que el diálogo que este arzobispo estableció con la Santa Sede, en ocasión de la ejecución del tercer concilio, estuvo dirigido a consolidar un estilo de gobierno metropolitano tendiente a proteger su autoridad episcopal y garantizara su predominio frente a otros sectores de la iglesia local. Esto lo hizo principalmente salvaguardando su jurisdicción episcopal y su rango de acción como arzobispo metropolitano.

2 Algunas obras que abordan el tema son: Severo (1958), Tineo (1996), Villegas (1975), Saranyana y Alejos Grau (1999), Fernández Terricabras (2000), Estenssoro Fuchs (2003), Pérez Puente (2007), López Lamerain (2011a), Vizuete Mendoza (2014), Cobo Betancourt (2014) y Moutin (2016). 


\section{El panorama de la Iglesia Peruana EN El siglo XVI}

Como es conocido, el proceso de conquista del Perú fue poco apacible, lo cual no fue diferente en términos eclesiásticos. En este contexto comenzó la discusión sobre el predominio de la ciudad del Cusco como sede de gobierno del Perú. Había sido la capital del imperio inca, y las luchas entre conquistadores giraban en torno a su anhelo de dominio sobre la ciudad. También entre los eclesiásticos hubo rencillas en este aspecto: el obispado del Cusco había sido erigido en 1537, antes que el de Lima (1541), pensándose primigeniamente como centro neurálgico de la naciente Iglesia peruana. Sin embargo, para dar fin a los conflictos internos, en 1542 Carlos V creó el virreinato peruano como estructura de gobierno territorial, estableciendo su capital en Lima o la «Ciudad de los Reyes». Desde entonces esta sería también la sede principal de la jerarquía eclesiástica. Antes de este proceso de estructuración, las órdenes franciscana y dominica habían estado activas en el territorio, ${ }^{3}$ y continuaron teniendo gran predominio, dando espacio más tarde a la Compañía de Jesús, que participaría activamente en la

3 La historiografía sobre la historia de la Iglesia en el Perú ha establecido una periodización sobre los procesos llevados a cabo en el virreinato. Se concibe una primera fase desde la conquista del Perú en 1532 a la celebración del primer concilio provincial de Lima, en 1551. Estaría caracterizada por practicar una evangelización masiva a los indígenas de la zona por parte de las órdenes mendicantes, al mismo tiempo que comenzaba a establecerse la jerarquía eclesiástica. Posteriormente, desde 1551 a 1606 se habría vivido un período «constitutivo» que organizó de una forma más eficaz los métodos de evangelización indígena y la estructuración de la Iglesia diocesana. 1606 marcaría el término de esta época, con el término del gobierno de Toribio de Mogrovejo sobre el Arzobispado de Lima. A él se ha atribuido, casi exclusivamente, la organización de la provincia eclesiástica del Perú. Estas periodizaciones se desprenden de autores como Armas Medina (1953); asimismo, véanse: Vargas Ugarte (1953, p. 148) y Luque Alcaide (2008, p. 33). Estenssoro Fuchs (2003) revisa estos procesos desde una perspectiva más crítica. Véase también la introducción de la Instrucción para curas de indios de Jerónimo de Loaysa, citada en Vargas Ugarte (1951, p. 139). 
organización eclesiástica desde su arribo al virreinato en $1568 .{ }^{4}$ Fue así como el obispado de Lima fue adquiriendo progresiva relevancia política, y así se explica su elevación a archidiócesis en 1546. Fue el dominico Jerónimo de Loaysa, primer obispo y luego arzobispo de Lima, figura clave de este período. ${ }^{5}$ Electo obispo en 1541, se trasladó a su diócesis en 1543, donde levantó la catedral e instituyó las primeras dignidades del cabildo catedralicio (cfr. Martínez Ferrer y Alejos Grau, 1999, pp. 119; y Vargas Ugarte, 1953, pp. 148-150). Impulsó la fundación de un seminario diocesano ${ }^{6}$ y de la universidad de San Marcos (cfr. Delgado Criado, 1993, pp. 372375), que posteriormente adquiriría gran prestigio. Desde 1546 su gobierno episcopal fue también metropolitano, convirtiéndose Lima en una de las tres archidiócesis del continente americano junto con Santo Domingo y México.

En cuanto a la creación de normatividad canónica, Loaysa convocó el primer concilio provincial de Lima (1551-1552) (cfr. Tudini, 2018). Fue la primera iniciativa concreta para responder de una manera sistemática a los problemas pastorales y disciplinarios de la provincia mediante la reunión con los obispos sufragáneos. ${ }^{7}$ El

4 Una de las primeras obras completas sobre la historia de los jesuitas en el virreinato es la de Vargas Ugarte (1965). Más recientemente contamos con las publicaciones de Burrieza (2004, 2007).

5 Nacido en Trujillo hacia 1498, Loaysa entró a la orden de predicadores y realizó sus estudios en Sevilla y Valladolid, donde fue discípulo de Francisco de Vitoria. Estaba emparentado con dos dominicos que obtuvieron alto renombre en el contexto indiano: fray Domingo de Mendoza, uno de los primeros frailes dominicos en trasladarse al Nuevo Mundo, y fray García de Loaysa, su tío, que llegó a ser presidente del Consejo de Indias. Se embarcó a América en 1529 y se instaló en Santa Marta, donde fundó un primer convento dominico. Luego se trasladó a Cartagena de Indias, donde fue presentado para obispo de la misma diócesis en 1537. Cfr. Acosta (1996, pp. 53-71, 54-56).

6 Pérez Puente (2017) ha estudiado la significación de los seminarios diocesanos como centros neurálgicos del poder episcopal.

7 Las resoluciones de esta primera asamblea se estructuraron en constituciones, dirigidas para españoles y para indios por separado. En términos generales, el 
difícil contexto político del Perú provocado por las guerras civiles entre los encomenderos españoles y la autoridad real hizo que, a pesar del avance organizativo que se había logrado en el concilio, se opacase en la práctica. En este tiempo, además, desde el Consejo de Indias se planeaba una restructuración de los planes de gobierno en todos los territorios. Más tarde, el tercer concilio provincial de Lima (1581-1582) derogó las constituciones del primero, por considerarlas ya añadidas al segundo concilio (1567-1568). Por lo tanto, puede decirse que sus disposiciones, al ser incorporadas a los decretos de las sucesivas reuniones provinciales, continuaron vigentes (cfr. Severo, 1958, p. 12). Las discusiones se irían complejizando, sobre todo en los concilios que se celebraron posteriormente, después del término del concilio ecuménico en 1563.

concilio se refirió sobre los grandes temas que se hallaban en la agenda de discusión de ese momento: la necesidad de un catecismo unificado, las reducciones en pueblos y doctrinas, la dignidad material de las iglesias, los sacramentos que debían administrarse a los indios, consideraciones sobre el matrimonio que tenían los indígenas que era necesario reducar, el modo de realizar los entierros, entre otras. Al clero que se enfrentaba a la evangelización, se mandó evitar la itinerancia y a residir en los pueblos de indios. También se dirimió sobre el financiamiento de las doctrinas, que debía correr por parte de los encomenderos, resolución que fue siempre fuente de conflicto en todas las localidades de la provincia. Por último, se trató sobre la distribución de las doctrinas entre el clero regular y el secular, medida que demuestra una mayor estructuración de las jurisdicciones de ambos cleros hacia la mitad del siglo XVI en el virreinato. Ver el texto completo del concilio en: Vargas Ugarte (1952, pp. 37-93). Como resultado visible de este primer concilio provincial se cuenta con la redacción de una cartilla catequética única traducida al quechua, principal lengua de la provincia, además de una Instrucción para párrocos a seguirse para enseñar la fe a los indígenas. Las constituciones para españoles, y sobre todo para clérigos, fueron de carácter disciplinar, para dar orden a la administración de las iglesias, a la liturgia y a la celebración de fiestas religiosas. Sobre las resoluciones pastorales véase sobre todo la monografía de Tineo (1990, pp. 80-130). 


\section{Trento ABRE UNA PUERTA}

La historiografía denomina el período que se inicia con el término del concilio ecuménico celebrado en Trento como la «era tridentina», ${ }^{8}$ definida habitualmente como un momento de centralización de poder del papado (cfr. Caiazza, 1992, p. 166) y caracterizada por un fortalecimiento de las estructuras internas de la curia romana. Por estos atributos, se considera una Iglesia con una mirada más aguda a los territorios recientemente conquistados por las potencias europeas, y partícipe de la expansión del catolicismo a lugares antes impensados. ${ }^{9}$

Desde la perspectiva de la Santa Sede, la Iglesia en Indias debía estar enfocada en la evangelización. La reforma propuesta en Trento, aplicada a las particularidades de los nuevos contextos ultramarinos, tendía a reforzar a la diócesis como núcleo de acción organizativa. Por eso la «tridentalización» de la Iglesia Universal, que en todo el mundo católico fortaleció el rol de los obispos, en América les dio mayor fuerza en la conformación de los entonces jóvenes gobiernos diocesanos. El ecuménico coincidió además con un afianzamiento del Patronato regio como fundamento de una nueva administración eclesiástica para las Indias, lo que fue marginando progresivamente la participación de la Santa Sede en América, ${ }^{10}$ ya

8 El término «era tridentina» es utilizado frecuentemente por la historiografía para caracterizar el catolicismo reformado que habría tenido lugar luego de la celebración del Concilio de Trento, y que habría tenido una larga duración. El término ha estado sujeto a revisiones por autores como Ditchfield $(2011,2013)$ y O’Malley $(2000,2002)$, aunque se continúa utilizando en un sentido temporal amplio.

9 Véase el caso del imperio portugués en Barreto y Zupanov (2015).

10 Así lo explica el académico Martínez Ferrer (2009, p. 41): «El sistema patronal, clave para entender la acción de la Iglesia en América, desplegó sus potencialidades y mostró sus límites: hizo posible el armazón institucional con el apoyo económico y logístico, pero dificultó las relaciones directas entre América y la Santa Sede». 
que Felipe II concebía la reforma tridentina como un paso necesario de su propia política eclesiástica. ${ }^{11}$ Como parte de la misma es que confirmó los decretos tridentinos y los aplicó como leyes en sus territorios en $1564,{ }^{12}$ y en ese contexto fueron los segundos concilios provinciales de México (1565) y de Lima (1567-1568) los convocados para dilucidar la mejor manera de implementarlos.

En el Perú tocó a Jerónimo de Loaysa congregar el segundo concilio provincial en Lima, en 1566. En ese entonces el número de diócesis sufragáneas del arzobispado eran nueve, habiéndose incorporado las del Cusco, Quito, Panamá, Popayán, Nicaragua, La Plata, Paraguay, Santiago de Chile y La Imperial. ${ }^{13}$ Sin embargo, a pesar de haber sido la primera vez que los decretos del tridentino fueron reflexionados en el contexto americano, este concilio provincial no tuvo mayor aplicación práctica en los años sucesivos a su celebración (cfr. Saranyana, 1999, p. 143). Una posible explicación a esto puede encontrarse en el contexto de los virreinatos a fines de la década del 1560, en que se llegó a un punto de inflexión en la administración de las Indias. Teniendo ya la experiencia de más de medio siglo, se hizo una revisión de lo conseguido hasta entonces.

Mientras tanto, la Santa Sede había adquirido amplia información sobre los asuntos americanos, ${ }^{14}$ tanto por vía de las órdenes

11 Concepto desarrollado por Kamen (1998). En palablas de González González (2010, p. 144): «El mismo afán centralizador llevó a la Corona a impulsar la primacía del clero secular, mucho más dócil a los mandatos reales que las poderosas órdenes religiosas».

12 La cédula de Felipe II de 1564 se encuentra citada en Tejada y Ramiro (1859, p. 1).

13 Cfr. Trujillo Mena (1981, p. 72). El elenco de diócesis sufragáneas se encuentra en el prólogo del texto del segundo concilio de Lima, citado en Vargas Ugarte (1952, p. 97).

14 Sobre esto explica Merluzzi (2007, p. 186): «The definition, demarcation and defense of the King's jurisdiction took place both inside and outside the kingdom, generating a series of jurisdictional conflicts with the papacy and creating a rift due to the clash between the theocratic aspirations of the Holy See in a post-Tridentine age and the concept of sovereignty on which the Spanish 
religiosas, primeras responsables de la evangelización, como posteriormente por la iglesia diocesana, en plena fase de expansión en el siglo XVI. Por otra parte, a nivel local, las tensiones entre el clero secular y el regular incrementaban, al coincidir frecuentemente en responsabilidades y jurisdicciones. Desde la perspectiva de la Corona, el panorama se presentaba grave: tras décadas de inversión de recursos - materiales, humanos y pecuniarios - en la evangelización de los pueblos indígenas, se corroboraba que tal tarea no se estaba acometiendo como se esperaba. En el Perú, por ejemplo, muchos indígenas habían vuelto a venerar a sus antiguos dioses, evidenciando que sus antiguas prácticas religiosas no habían sido erradicadas. El proyecto misional claramente estaba fracasando, lo que presentaba un problema real a la monarquía. Las razones de este estado de cosas son variadas, aunque se culpabilizó principalmente al duro régimen de trabajo impuesto a las comunidades indígenas. En este punto, las tensiones entre el papado y la corona española comenzaban a hacerse más visibles. Felipe II quiso subsanar estas falencias por él mismo, limitando la acción de la Santa Sede en sus dominios ultramarinos, y en 1568 convocó una junta para deliberar sobre los cambios que se requerían. Algunas de las instrucciones de orden eclesiástico fueron la resolución de aumentar el número de obispados para las provincias americanas, la creación de nuevas escuelas y templos, y una nueva regulación para los diezmos. ${ }^{15}$ Los concilios provinciales también fueron un tema capital de discusión

Crown rested». Sobre el tema comenta también Pedro Leturia: «Cuando después del concilio de Trento los grandes papas de la restauración católica volvieron plenamente los ojos al campo de las misiones, tropezaron en el Consejo de Indias con una tradición ya formada, que trataba precisamente en la Junta de 1568 de plasmar en formas definitivas, y que no era fácil se dejase transformar ni menos absorber por la nueva actividad más eclesiástica de la Curia romana» (Leturia y Egaña 1959, p. 84). El primer estudio sistemático sobre esta junta es el de Ramos Pérez (1986).

15 La administración de los diezmos fue una cuestión discutida desde los comienzos de la organización de la Iglesia americana, hallándose las opiniones dispares 
en la junta: el mandato del Concilio de Trento de que estas reuniones se celebrasen con mayor regularidad sirvió a Felipe II para inmiscuirse aún más en los temas eclesiásticos. Se hacía presente en ellos mediante las principales autoridades de los virreinatos, que tomaban parte activa de las reuniones sinodales. Fue de hecho el célebre virrey Francisco de Toledo la figura clave de este período de reforma extensiva del virreinato. ${ }^{16}$ Finalmente, la denominada Junta Magna acordó la instalación de tribunales inquisitoriales en América, lo cual se concretó en México y Lima el año 1569, y en Cartagena de Indias en 1610. Es probable que todos estos cambios institucionales eclipsaran la primera recepción tridentina en el segundo concilio limense (cfr. Trujillo Mena, 1981, pp. 74-76). No obstante, las piedras angulares de la reforma se hicieron visibles, sobre todo en el rol de los obispos, que a partir de entonces estaban obligados a realizar la visita episcopal, mantener la residencia en sus diócesis, crear seminarios diocesanos y perfeccionar la justicia diocesana. En torno a estas tareas y facultades se iría perfilando un modo de gobierno para la provincia, aunque como se intuye, con muchas partes interesadas en obtener cuotas y parcelas de poder.

\section{Toribio de Mogrovejo Recurre A Roma}

Sin duda, los concilios provinciales fueron clave en la creación de un gobierno eclesiástico ejemplar para los demás obispados de la provincia. En ellos se discutía y planificaba no solo sobre la pastoral a implementar en las diferentes diócesis, sino también sobre cómo crear una organización administrativa uniforme y funcional. Como

sobre esta. El monarca, mediante la Junta, intentó zanjar definitivamente la situación. Cfr. Leturia y Egaña (1959, pp. 70-71).

16 Sobre la injerencia del virrey Toledo en la Junta Magna véase Merluzzi (2014, pp. 86-110). 
parte de este proceso, el arzobispo de Lima buscó fortalecer su posición tanto en el ámbito eclesiástico como en el seglar. ${ }^{17}$ Para ello no solo negoció con los poderes locales y peninsulares, sino que también buscó el apoyo de Roma.

Como segundo arzobispo de Lima, a Toribio de Mogrovejo se le encomendó continuar con la organización de la Iglesia peruana y con la incorporación de la reforma tridentina en la región, como se planeó desde las nuevas políticas eclesiásticas de Felipe II. Mogrovejo es considerado hasta hoy un símbolo de la edificación del episcopado americano. Fue beatificado poco después de su muerte, en 1679, bajo el pontificado de Inocencio XI, y canonizado por Benedicto XIII en 1726. En 1983 fue instituido por el papa Juan Pablo II como Patrono del Episcopado Americano, lo que demuestra la trascendencia de su gobierno episcopal. La literatura existente sobre su vida, su labor pastoral y su influencia en el ámbito religioso y político es profusa y como personaje ha sido abordado por la historiografía desde diversas perspectivas. ${ }^{18}$ Su participación en el tercer concilio de Lima (1582-1583) fue igualmente enaltecida, atribuyéndosele a él, junto a otros personajes ilustres de la época — como el jesuita José de Acosta-, la creación de una normativa disciplinar y evangelizadora estable, eficiente y perdurable en el tiempo para Sudamérica. ${ }^{19}$

17 Esto también en el plano económico y de las relaciones de poder en la sociedad de Lima, véase el detalle en Acosta (1996).

18 Las tendencias historiográficas que predominan en las obras que tratan sobre Mogrovejo son las que resaltan los atributos que le habrían llevado a la santidad, y otras más críticas. Hay publicaciones que toman un aspecto específico de su gobierno, ya sean las visitas pastorales que realizó, su relación con la política o su promoción de la evangelización. Se han realizado también muchas transcripciones de documentos y fuentes ligadas a él, realizadas sobre todo durante el siglo XX. La multiplicidad de títulos existentes sobre el arzobispo refleja la variedad de perspectivas con que se ha abordado. Véanse, por ejemplo: Rodríguez Valencia (1957), McGlone (1993), Benito (2006), Autores Varios (2007) y Grignani (2009).

19 Sobre la normativa evangelizadora generada por el tercer concilio de Lima véase López Lamerain (2011b). 
Me ocuparé aquí de un aspecto específico de su gobierno: la jurisdicción episcopal. ${ }^{20}$ Este tema se presenta especialmente en una de las comunicaciones que Mogrovejo envió a la Santa Sede luego de celebrarse el tercer concilio provincial en Lima, en que presentó dudas relativas al gobierno metropolitano que habían surgido en la misma reunión conciliar. Esto se relaciona con el objetivo del arzobispo de que el texto final de los decretos conciliares obtuviese la aprobación pontificia, que se confirmó finalmente en 1588. Por su parte, la Corona dio su autorización al texto en 1591. En estos intercambios entre el arzobispo y la curia romana destacó la intención de Mogrovejo de que el pontífice confirmara los límites de su gobierno metropolitano, en gran medida propuestos por él mismo. A mi modo de ver, estudiando estos detalles puede reconstruirse el modelo episcopal que el arzobispo intentaba cimentar para la provincia, refinando también las herramientas de gobierno de sus obispados sufragáneos.

En este punto se hace necesario aclarar cómo se conformaba la jurisdicción de los obispos en el contexto de la reforma tridentina. Según Maximiliano Barrio Gozalo:

El nuevo modelo se concretiza en la figura del buen pastor que cuida de sus ovejas y las gobierna con caridad. En consecuencia, el obispo debe ser un perfecto discípulo de Cristo y modelo de santidad, pues por el puesto que ocupa se vuelven hacia él las miradas de todos los fieles [...]. Y en segundo lugar, la misión episcopal se debe desplegar en tres causes fundamentales, cuales son el enseñar, santificar y regir. ${ }^{21}$

20 Aunque la jurisdicción episcopal en América fue algo que se fue construyendo en el tiempo, tenía como base las competencias que el Concilio de Trento había dado a los obispos. Las más importantes, la de realizar la visita pastoral, la de ser juez ordinario de asuntos eclesiásticos en primera instancia, la de imponer castigos. Cfr. Moutin (2009, pp. 1-25, 17-20) y Dougnac (1994, pp. 299-300).

21 Barrio Gozalo (2010, p. 296). 
Efectivamente, sus poderes se desenvolvían en los ámbitos legislativo, judicial, ${ }^{22}$ doctrinal y administrativo, siendo en su diócesis la máxima autoridad eclesiástica. ${ }^{23}$

Toribio de Mogrovejo había ocupado la sede metropolitana en 1581, tras la muerte de Jerónimo de Loaysa en 1575 y un breve periodo de sede vacante. En 1581 también arribó al Perú el recién nombrado virrey Martín Enríquez de Almansa. La llegada de ambas figuras para encargarse del «gobierno temporal y espiritual» del virreinato dio fuerza a los cambios que buscaba implementar la Corona en ambos planos. De hecho, Mogrovejo convocó el concilio provincial nada más llegar a Lima. Por supuesto, su celebración no estuvo exenta de complicaciones. La aprobación real y papal de los decretos conciliares hubo de recorrer un largo camino debido a las numerosas disputas entre los grupos involucrados en el sínodo. ${ }^{24}$ Estas se transformarían luego en apelaciones formales a varios de los decretos del concilio provincial. Para evitar que se perdiese todo el esfuerzo vertido en el concilio y se lograse su aprobación lo más rápido posible, Toribio de Mogrovejo se apresuró en desplegar sus influencias en las cortes de Madrid y Roma. ${ }^{25}$ La premura del

22 Explica Terráneo (2015, p. 359) que «es, precisamente, el obispo el único juez en su diócesis y detenta toda la potestad. Ningún texto conciliar americano permite sospechar, ni aun remotamente, que la potestad judicial de los prelados pudiera ser extendida a otros órganos eclesiásticos».

23 Como sostiene Traslosheros (2014, p. 21): «Los obispos estaban obligados a enseñar las reglas de la costumbre y religión cristiana, administrar los sacramentos, decidir en cuestiones de doctrina, formar cánones o suprimirlos para confirmar la creencia o arreglar las costumbres, sancionar y establecer ritos sacramentales y otras ceremonias sagradas, nombrar pastores y ministros de culto o deponerlos en caso necesario, amonestar a los pecadores cristianos y, en casos extremos, podían separar del cuerpo de la Iglesia a los pecadores». Cfr. La voz «Évêques» en Naz (1953, pp. 579-581).

24 Véase en detalle el contenido de los pleitos en Trujillo Mena (1981, pp. 86-104).

25 Una descripción de los acontecimientos en Martínez Ferrer (ed.) y Gutiérrez (trad.) (2017, pp. 51-58). 
arzobispo logró que ya en diciembre de 1583 se contara con una traducción castellana del concilio, y que las apelaciones al mismo comenzaran a realizarse a partir de $1584 .{ }^{26} \mathrm{Al}$ mismo tiempo que se interponían los recursos, Mogrovejo enviaba misivas para contrarrestarlos, ya que las demandas se debatían en ambas cortes simultáneamente. Como indica una comunicación que el arzobispo Loaysa envió a Roma después del segundo concilio limense, no era la primera vez que desde la Ciudad de los Reyes se recurría a la curia romana. Es más, desde los inicios de su gobierno, Mogrovejo buscó mantener una comunicación directa y fluida con la Santa Sede $^{27}$ para validar las acciones de su gobierno. No detallaré aquí las apelaciones que se hicieron desde los obispados sufragáneos al texto conciliar, las que también fueron examinadas por la Congregación del Concilio, ${ }^{28}$ dicasterio de la curia romana encargado de contestar dudas acerca de los decretos disciplinares del Concilio de Trento, ${ }^{29}$ además de reconocer (recognitio) y validar los textos conciliares

26 Las realizadas por los cabildos catedrales de los obispados sufragáneos en concreto son tratadas en Martínez Ferrer (2015). Y más recientemente, el mismo autor (Martínez Ferrer, en prensa) ha analizado en profundidad las peticiones que Domingo de Almeyda llevó ante Roma y Madrid.

27 Sobre lo que expone Vicente Rodríguez Valencia (1957, p. 148): «Instauró un contacto simultáneo, asimismo constante y directo, con Roma, no ya en la asiduidad de las visitas ad Limina por procurador, ni sólo en las cuestiones de gobierno, sino en el detalle a que se presenta mejor el género epistolar, manteniendo correspondencia y los cardenales de las congregaciones romanas, así como también con los superiores mayores de las Ordenes religiosas residentes en Roma, como intermediarios eventuales. Apenas hay un paso importante de gobierno que no haya sido sometido al refrendo de la Santa Sede en trámite directo. Y eso es ya característico».

28 Cfr. AAV [Archivo Apostólico Vaticano], Congr. Concilio, Positiones, vol. 58, ff. 348r/v; 373r/v. La súplica está dirigida al cardenal Antonio Carafa, entonces prefecto de la Congregación del Concilio y está remitido desde la Ciudad de los Reyes a favor del clero, contra los arzobispos sufragáneos (f. 353v). El documento no está fechado.

29 Véase Romita (1964). 
(cfr. Martínez Ferrer, 2001). Los cabildos catedrales y el clero secular habían utilizado este medio para protestar sobre la rigidez de algunos decretos disciplinares, considerándolos expresión de un poder abusivo por parte de los obispos. Como se ve, en la aprobación del tercer concilio limense se desenvolvía una fuerte pugna entre los poderes locales del virreinato peruano. ${ }^{30}$ Tras varios reveses, prevalecieron las gestiones del arzobispo de Lima para la defensa, entrega y aprobación del texto conciliar en Roma. Pero años antes de que esto ocurriera, la misma congregación ya había estado en contacto con las temáticas canónicas del tercer concilio mediante una serie de consultas que el mismo Mogrovejo le había hecho llegar en 1585.

El documento al que me refiero es conocido y ha sido trabajado tanto en el ámbito canónico como por la historiografía, ${ }^{31}$ al

30 Esta no fue una situación restrictiva al virreinato peruano, sino también en la Nueva España durante la celebración del Tercer concilio mexicano de 1585. Véase un ejemplo en Ortiz Treviño (2003).

31 Cfr. Rodríguez Valencia (1956-1957, nota 6 en pp. 149-150). En 1653, Antonio de León Pinelo publicó la primera obra biográfica de Toribio de Mogrovejo en la que explicita: «he hallado estas dudas, i las Declaraciones, que a ellas dio la Sacra Congregacion de los Eminentissimos Cardenales, Interpretes del Concilio Tridentino: me ha parecido referirlas, en este capitulo fielmente; assi por ser tan proprias del estudio, i gobierno de nuestro Arçobispo, como por ser en comprobación, de lo que afirman tantos testigos; i aun de lo que dexamos escrito. Las dudas fueron treinta i siete; puestas a la Santidad de Gregorio Decimotercio, aunque determinadas en tiempo de Sixto Quinto, que le sucedió, por el año de mil i quinientos i ochenta i seis. De que el Arçobispo D. Fernando Arias de Ugarte hizo sacar copia autentica en Roma; la qual pasò por el Consejo Real de las Indias, en cuya Secretaria ay trasunto dellas; i son estas» (pp. 151-152). Como señala el mismo León Pinelo, el texto que transcribe es la copia y traducción realizada por el Consejo de Indias, por lo que las dudas y respuestas se presentan en castellano. Esta copia oficial se encuentra en el Archivo General de Indias (AGI, Lima, 300). Por su parte, Francisco de Haroldo, padre franciscano que en 1673 publicó las constituciones de los sínodos provinciales y diocesanos celebrados por Toribio de Mogrovejo, titulada Lima Limata Conciliis, constitutionibus synodalibus et allis momumentis, quibus venerab. servus Dei Toribius Alphonsus Mogroveius archiepisc., transcribió las dudas que el arzobispo envió a la congregación del 
considerarlo un precedente en varios aspectos. Al exponer aquí las célebres treinta y siete preguntas de Mogrovejo, pretendo afirmar la idea de que, mediante el envío de estas dudas de carácter canónico, el arzobispo de Lima buscó afirmar las bases asentadas en el tercer concilio provincial sobre la autoridad y jurisdicción episcopal. Las respuestas de Roma le servirían luego para fortalecer su argumento y ampliar el rango de acción de los obispos de la provincia, y para contrarrestar los ataques de otros sectores de la Iglesia local.

El documento forma parte de la serie archivística Positiones Sessiones del archivo de la congregación del Concilio, cuyos volúmenes están organizados según los cánones de reforma del Concilio de Trento a los que aludían los casos. Al tener que examinar dudas, solicitudes y resolver problemas que pudiesen surgir de la interpretación de los decretos de reforma del ecuménico, durante sus

concilio junto con las respuestas de la congregación, en latín, extraídas de Libri Decretorum, volumen 4, del archivo de la congregación del Concilio. La transcripción íntegra se encuentra en las páginas 124-129. Por su parte, en el siglo XX, la biografía del arzobispo de Lima realizada por Carlos García Irigoyen (1906-1907, p. 118) refiere que: «Gobernado la Iglesia la Santidad de Gregorio XIII, el arzobispo don Toribio, varón á todas luces prudentísimo, á quien no hinchaba la ciencia de este mundo y que no buscaba sino el acierto en todas las cosas, sometió á la consulta de Roma, columna y fundamento de la verdad, las treintaisiete dudas que dicen así». Las dudas se presentan en castellano, aunque no corresponde exactamente a la transcripción hecha por León Pinelo. Falta, de hecho, la duda número 23. Aclara que: «Las declaraciones de estas dudas solo se alcanzaron en tiempo de Sixto V, recibiéndolas el Consejo Real de las Indias el Illtmo. señor Lobo Guerrero, sucesor de nuestro Toribio», p. 125. En nota aclara que fueron expedidas en Roma el 27 de julio de 1666. Roberto Levillier (1919) incluyó una referencia a las dubia de Mogrovejo en su obra recopilatoria de documentos provenientes del Archivo General de Indias (AGI). Se trata de un testimonio del traslado de tres de las dudas (21, 22 y 23) tocante a regulares, fechado en Lima, el 23 de marzo de 1591. Incluye además un traslado de letras ejecutoriales de parte de Camillo Borghese, oidor de la Cámara Apostólica, enviado a Toribio de Mogrovejo con las respuestas a las 37 dudas, fechado en Roma en 1592. Asimismo, Rodríguez Valencia (1956-1957) transcribe algunas de las dudas presentadas por el arzobispo. 
primeras décadas de funcionamiento (hasta 1681), la congregación ordenó los casos en su archivo por sesión y canon de reforma sobre el que debía deliberar. De hecho, todas las comunicaciones que le fueron enviadas desde Lima después de celebrados los concilios provinciales que siguieron al tridentino ${ }^{32}$ se encuentran catalogadas en la sesión 24, capítulo 2 , de la reforma que mandaba a que los concilios provinciales se celebrasen cada tres años. ${ }^{33}$

Escrito íntegramente por miembros de la congregación, en sus primeras líneas el documento explica que las preguntas expuestas habían sido contestadas en 1585, a petición del mismo arzobispo Mogrovejo, y a quien se habían remitido las contestaciones en 1586. ${ }^{34}$ Pero a causa de los problemas de la navegación y caminos, las cartas llegaron a él incompletas, y por esto él había solicitado una copia oficial del documento original. ${ }^{35}$ Es importante destacar que dichas resoluciones no solamente estaban dirigidas al arzobispo

32 Cfr. AAV, Congr. Concilio, Positiones, vol. 103, ff. 197r/v; 205r-209v, y del mismo volumen, ff. 189r/v (correspondientes al segundo concilio limense, gobierno de Jerónimo de Loaysa); AAV, Congr. Concilio, Positiones, vol. 107, ff. 14r-15v (petición de Toribio de Mogrovejo sobre periodicidad de los concilios provinciales fechada en 1581); AAV, Congr. Concilio, Positiones, vol. 108, ff. 29r-30v; 36r-37v (las treinta y siete dudas de Mogrovejo); AAV, Congr. Concilio, Positiones, vol. 58, ff. 368r/v; 373r/v (clero de las diócesis sufragáneas contra algunos decretos del tercer concilio de Lima), y cuatro casos correspondientes al siglo XVII.

33 Si bien es verdad que todos los temas de las misivas enviadas se relacionaban de alguna u otra forma con la celebración de concilios provinciales, los contenidos de estas comunicaciones resultan ser mucho más amplios que los que se derivan del canon mismo: «Celébrese de tres en tres años sínodo provincial y todos los años diocesano. Quiénes son los que deben convocarlos y quiénes asistir». Vid. López de Ayala (1857, pp. 322-323).

34 AAV, Congr. Concilio, Libri Litter., vol. 6, ff. 98r/v.

35 «Illustrissimi Domini, infrascripta dubia fuerunt alias et de anno 1585 ad instantia Reverendissimi Domini Toribii Alphonsi Mogrovejo, archiepiscopi Civitatis Regum in Indiis novis maris del sur decisa per Illustrissimos DD. Cardinales interpretes decretorum sacri Concilii Tridentini et fuerunt sibi transmissa inclusa in hiis missivis quae propter longa discrimina viarum et navigationis [¿vitiate?] 
de Lima, sino también a los obispos sufragáneos de la provincia eclesiástica del Perú. ${ }^{36}$ Aunque el expediente no contiene datos de su fecha de elaboración, en la serie Libri Decretorum del archivo de la congregación —que incluye copias de todos los decretos emitidos por el dicasterio_-, se comprueba que las respuestas, en forma de decretos, fueron dictadas nuevamente en $1592 .{ }^{37}$ La mayoría de las dudas de Mogrovejo son materia de gobierno metropolitano (cfr. Albani, 2009, p. 69), y están estrechamente relacionadas con los acontecimientos ocurridos durante y después de celebrarse el tercer concilio de Lima.

En primer término, el arzobispo consultaba a la congregación cuál era su posición en el concilio provincial. Específicamente, sobre cuál era el alcance jurídico del metropolitano en la asamblea —además de ser su presidente_, y cuáles eran los límites de su autoridad frente a los obispos sufragáneos y frente al mismo concilio como institución colegiada. Muy probablemente, Mogrovejo buscaba evitar que en el futuro sucediera lo que pasó en la primera etapa del concilio, donde se presentaron numerosas causas criminales contra algunos obispos para que fuesen resueltos por el concilio, adquiriendo este la función de tribunal eclesiástico. La disputa más célebre fue la que ocurrió en torno a Sebastián de Lartaún, obispo del Cusco. Durante las primeras sesiones, los vecinos del Cusco y parte del clero secular de la diócesis presentaron demandas contra el obispo y entregaron largos memoriales para ser discutidos en el concilio provincial. Incluso el cabildo secular del Cusco hacía parte de las acusaciones, siendo los delitos más

pervenerunt ad eius manus supplicat sibi dari copiam in publica forma ita ut illis et credi possit» (AAV, Congr. Concilio, Positiones, vol. 108, f. 29r).

36 Puede leerse: «supplicat Illustrissimis DD. Cardinalis sacrae Congregationis Concilii Tridentini quatenus dignentur respondere, quid per ipsum et episcopos suffragantes tenendum sit in infrascriptis dubitationis» (AAV, Congr. Concilio, Positiones, vol. 108, f. 29r).

37 AAV, Congr. Concilio, Libri Decret., vol. 7A, ff. 46-47. 
graves que se le imputaban, los de homicidio y simonía. La disputa provocó la formación de dos bandos en el seno del concilio, uno a favor de Lartaún y el otro a favor de Mogrovejo. Al primero le apoyaban los obispos de La Plata, de Tucumán y posteriormente el de Quito, y también parte importante de la Audiencia de Lima. De parte del arzobispo se encontraba Antonio de San Miguel, obispo de La Imperial en Chile, y algunas autoridades reales. El conflicto adquirió tintes escandalosos cuando el arzobispo quiso enviar la causa a Roma para que fuese resuelta directamente por la Santa Sede, y el obispo de Tucumán se negó a entregar los papeles del caso, escondiendo para ello la llave del archivo. Además de que, en una oportunidad, los obispos disidentes intentaron reasumir las sesiones del concilio en ausencia del arzobispo. Para continuar con las reuniones, luego de numerosas recusaciones y excomuniones de por medio, la audiencia solicitó que se levantaran todas las censuras y las sesiones lograron retomarse en abril de 1583. Sebastián de Lartaún murió durante el concilio, en marzo de $1583 .{ }^{38}$

Esta situación explicaría algunas interrogantes presentadas por el arzobispo a Roma. De hecho, indagaba en sus misivas si era posible que el concilio provincial conociera en primera instancia los casos — civiles y criminales — de los obispos sufragáneos. ${ }^{39}$ En sus respuestas la congregación del concilio aclaraba que el concilio provincial sí podía conocer las causas de los sufragáneos en los casos que mandaba expresamente el Concilio de Trento, en las causas civiles y criminales que fueran de resolución rápida, y en los casos del metropolitano que estuvieran pendientes. Sin embargo, el sínodo provincial no podía adjudicarse causas que ya hubieran

38 Sobre este conflicto véanse Vargas Ugarte (1959, pp. 56-71), Vizuete Mendoza (2014, p. 180) y Azamburu-Zudaire (1990, pp. 385-387).

39 «Primo an concilium provincialem possit cognoscere de omnibus causis vertentibus in prima instantia coram episcopis suffraganeos» (AAV, Congr. Concilio, Positiones, vol. 108, f. 29r). 
sido introducidas en primera instancia por los ordinarios. ${ }^{40}$ Sobre el concilio como instancia de apelación, preguntaba el arzobispo si podía serlo de causas pendientes de obispos —o sus vicarios- en caso de estar ausente el metropolitano, ${ }^{41} \mathrm{y}$ si este último igualmente debía apelar al concilio, o si debía hacerlo directamente al papa. ${ }^{42}$ La congregación señaló que, efectivamente, el concilio provincial era una instancia de apelación válida para los obispos en caso de que el arzobispo estuviera ausente, y lo era también para el propio metropolitano, quien además tenía la opción de elevar su apelación a la Santa Sede. ${ }^{43}$ No obstante, no era posible que el concilio apelara al arzobispo o a sus oficiales generales. Tras estas aclaraciones propiamente jurídicas, Mogrovejo continuaba planteando posibles situaciones a los que él — como arzobispo- podía poner remedio, como por ejemplo si podía, por causas justas, disolver el concilio sin el consentimiento de los demás obispos sufragáneos, ${ }^{44}$ o si podía proceder con censuras contra ellos si intentaban usurpar su jurisdicción. ${ }^{45}$ Sin duda, estos escenarios descritos son reminiscencias del momento en que los obispos sufragáneos de

40 «Congregatio Concilii censuit posse cognoscere non solum de his causis qu[a]e specialiter eius iudicio a iure et Concilio Tridentino reservatae sunt sed de omnibus tam civilibus quam criminalibus quae dubi non sint quaeque brevi tempore possunt expediri et alii qui iuxta canonicas sanctiones in ea tractari et definiri possunt, si tamen in prima instantia coram eorum ordinariis ille introductae reperiantur non posse avocari nisi in casibus et modis a iure permissis» (AAV, Congr. Concilio, Positiones, vol. 108, f. 29r).

41 «An de causis pendentibus coram episcopis vel eorum vicariis possit appellari ad concilium omisso Archiepiscopo» (AAV, Congr. Concilio, Positiones, vol. 108, f. $29 \mathrm{r})$.

42 «An possit appellari ab archiepiscopi ad concilium vel an debeat appellari ad papam» (AAV, Congr. Concilio, Positiones, vol. 108, f. 29r).

43 «Posse ad utrumque» (AAV, Congr. Concilio, Positiones, vol. 108, f. 29r).

44 " $A n$ archiepiscopus solus iustis de causis possit absque aliis episcopis dissolvere concilium» (AAV, Congr. Concilio, Positiones, vol. 108, f. 29r).

45 «An archiepiscopus possit procedere per censuras et alias penas contra episcopos illos qui usurparent archiepiscopi jurisdictionem in Concilio sive extra illud 
la provincia que apoyaron a Sebastián de Lartaún en el conflicto intentaron dejar fuera al arzobispo de las sesiones del concilio, celebrando algunas reuniones en su ausencia y en clandestinidad, expropiando su jurisdicción como metropolitano. De esta manera, Mogrovejo tanteaba hasta qué punto podía limitar las acciones de los obispos sufragáneos durante la ejecución de la asamblea. Sin embargo, a ambas consultas la congregación respondió de forma negativa; es decir, el metropolitano no podía clausurar el concilio sin la aprobación de los obispos sufragáneos, ni tampoco aplicarles censuras durante el mismo.

Avanzando un poco más allá de la contingencia del tercer concilio limense, Mogrovejo indagaba sobre los roles de cada una de las instituciones eclesiásticas en discusión (concilio provincialarzobispo-obispos sufragáneos) en el manejo de las causas judiciales presentadas, fueran estas graves o menores, criminales o civiles. Preguntaba a la congregación si el concilio provincial podía formar proceso contra un obispo que, durante este, fuese acusado con causas graves, para remitirlo luego al pontífice. ${ }^{46}$ Sobre ello la congregación respondía que podrían recogerse informaciones sumarias del caso de manera extrajudicial, y luego transmitírselas al papa. Por otra parte, sobre lo que el Concilio de Trento había establecido en la sesión 24, capítulo 5 de reforma, «las causas criminales menores de los obispos conózcanse, y termínense solo en el concilio provincial, ó por los que depute este mismo concilio»; ${ }^{47}$

volentes cognoscere de aliquibus causis tribunalis er curiae ipsuis archiepiscopi» (AAV, Congr. Concilio, Positiones, vol. 108, f. 29r).

46 «An Concilium provinciale poterit capere informationem aut formarem processum contra aliquem episcopum suspectum aut accusatum ibidem de causis gravioribus ad effectum transmittendi probationem et processum ad S.m D.N. Papam» (AAV, Congr. Concilio, Positiones, vol. 108, f. 29r).

47 Cfr. sesión XXIV, cap. 5 de reforma, «Conozca solo el sumo Pontífice de las causas criminales mayores contra los Obispos; y el concilio provincial de las menores», en López de Ayala (1857, pp. 329-330). 
el arzobispo inquiría si en el caso de nombrarse diputados para conocer estas causas, estos debían ser necesariamente obispos, a lo que la congregación respondió asertivamente, por la reverencia debida a los oficios pontificios. Esto funcionaría así a menos que el concilio propusiera otra cosa. ${ }^{48}$ En cuanto a las causas civiles de los obispos sufragáneos, consultaba Mogrovejo si el metropolitano podía conocerlas, y también si el concilio provincial podía conocer las causas menores del arzobispo, fueran estas civiles o penales. En el primer caso, la respuesta fue que solamente era posible en caso de que se actuara contra el obispo, ${ }^{49}$ y que el concilio no podía conocer las causas menores del metropolitano.

Como se ve, la congregación del concilio presentaba sus respuestas de manera escueta y directa, ceñidas estrictamente al derecho canónico y a la normativa tridentina, dando cuenta de un equilibrio entre las competencias de cada parte en consulta. Si bien la congregación dejaba claro al arzobispo los límites de su jurisdicción, no lo hacía en desmedro de las otras partes, que también podían interceder en asuntos de justicia. Tal vez Mogrovejo estaba adelantándose a las siguientes asambleas que convocaría, a los sucesivos concilios provinciales que congregaría en 1591 y 1601 , y a los — nada menos — trece sínodos diocesanos, en los que luego de recibir la contestación de la Congregación del Concilio, actuaría con pleno conocimiento de sus funciones y límites.

El segundo arzobispo de Lima también inquirió sobre la jurisdicción episcopal en relación con las órdenes regulares. Con ello retomaba conflictos ya planteados en concilios anteriores, $\mathrm{y}$

48 «Congregatio Concilii respondit, ob reverentiam pontificalis officii huiusmodi causas episcopis debere committi, si tamen Concilio provinciali aliter ex causa visum fuerit posse et non episcopos deputari» (AAV, Congr. Concilio, Positiones, Vol. 108, f. 29r).

49 «Posse quando agit contra episcopum, et ubi subditus episcopi agit contra episcopum, coeterique non posse, nisi in casibus a iure expressis» (AAV, Congr. Concilio, Positiones, vol. 108, f. 29r). 
de los que Jerónimo de Loaysa había dado cuenta a la Santa Sede años antes. Saltaban nuevamente a la palestra los beneficios que los pontífices habían conferido a las órdenes mendicantes durante las primeras décadas de evangelización; temas que además seguían generando controversias. Al igual que las preguntas sobre los alcances del concilio provincial como entidad institucional, Mogrovejo pretendía posicionar su jurisdicción por sobre las órdenes, ${ }^{50}$ sobre todo ante los religiosos que ejercían la cura de almas en parroquias o doctrinas que, según el Concilio de Trento, estaban sujetos a la jurisdicción del obispo. Refiriéndose a aquellos espacios que en la predicación estaban siendo compartidos por el clero secular y el regular, el arzobispo consultaba si los obispos podían visitar, corregir y castigar a los regulares que enseñaban la fe católica a los indios, basándose en el decreto del Concilio de Trento que establecía que los regulares que vivían fuera de los claustros podían ser corregidos y castigados por el ordinario. ${ }^{51}$ ¿Debían estos regulares declarar el vivir fuera del claustro para que el obispo pudiese corregirlos? ¿Podrían ser removidos por su superior sin el permiso del obispo? La congregación contestaba que el obispo sí podía castigarlos, y que los regulares encargados de realizar labor pastoral con los indios debían declarar vivir fuera del claustro. Su superior podía removerlos de ese cargo si le parecía necesario, pero esto debía ser comunicado al obispo. Continuaba en el mismo tenor al interrogar si los regulares nominados por los obispos para la evangelización de los indios debían ser examinados por quienes asignara el sínodo

50 Este tema ha sido analizado por Leturia (1930).

51 Se refiere expresamente al capítulo XI de reforma de regulares en la sesión 25: «En los monasterios que tienen á su cargo cura de personas seculares, estén sujetos los que la ejerzan al Obispo, quien deba antes examinarlos: exceptuándose algunos [...] estén las personas que tienen este cuidado, sean regulares ó seculares, sujetas inmediatamente en las cosas pertenecientes al expresado cargo, y a la administración de los Sacramentos, á la jurisdicción, visita y corrección del Obispo en cuya diócesis estuvieren», citado en López de Ayala (1857, p. 378). 
diocesano y el ordinario, o bastaba que lo hiciera únicamente el obispo. La congregación contestaba que, efectivamente, dichos regulares debían ser examinados por el ordinario.

No obstante, la pregunta veintitrés fue la que causó más polémica, ya que las contiendas sobre su contenido continuarían en el cuarto concilio provincial de Lima de 1592 (cfr. Rodríguez Valencia, 1956-1957, pp. 155-157). En ella el arzobispo consultaba si la bula de Pío V (pp. 1566-1572), que había sido otorgada para que los regulares administrasen los sacramentos a los indios sin previo examen del obispo, había sido revocada o no, al aplicarse una bula posterior que confirmaba estos privilegios en todo lo que no fuese contrario al Concilio de Trento. El arzobispo sustentaba esta duda en que dicho privilegio a todas luces contrariaba al concilio ecuménico. ${ }^{52}$ En esto —y he ahí la continuidad de la disputa— la congregación revocó la bula de Pío $\mathrm{V}$, por lo que los regulares debían ser examinados como lo prescribía Trento. Como era de esperar, las órdenes protestaron sobre esta situación en Roma solicitando nuevos breves de excepción, y llevaron el asunto al siguiente concilio provincial de Lima (cfr. Rodríguez Valencia, 1956-1957, p. 157).

El caso de las órdenes femeninas, en cambio, no presentó mayores complicaciones, porque estas estaban más visiblemente sujetas al poder episcopal, tanto en la visita de los monasterios, la elección de abadesas y los requerimientos de las monjas. Aun así, Mogrovejo presentó a la congregación una situación particular sobre

52 «An sit revocata bulla sive motus proprius fel. rec. Pii $\mathrm{V}^{\mathrm{t}}$ concessa ad instantia Cattholicae Maiestatis, ut regulares absque examine per episcopos faciendi possent administrare sacramenta indis, per aliam bullam S. ${ }^{\mathrm{mi}}$ Gregorii pp XIII in qua confirmantur privilegia ordinum mendicantium in his in quibus non sunt contraria Concilio Tridentino, et in hoc quod isti regulares non examinarentur ab episcopo ad administrationem sacramentorum, videntur este contraria Concilio ac propterea an debeant regulares examinari ab episcopo ad administrationem sacramentorum» (AAV, Congr. Concilio, Positiones, vol. 108, f. 29v). Se refiere al capítulo XI de reforma, de regulares en la sesión XXV. Véase en López de Ayala (1857, pp. 378-379). 
el que para entonces habría sido el único monasterio de monjas en Chile. ${ }^{53}$ El monasterio de Santa Isabel de Hungría de monjas clarisas había sido fundado en la ciudad fronteriza de Osorno en 1567, alrededor de 500 kilómetros al sur de Concepción y a 900 kilómetros de Santiago - entonces las principales ciudades de Chile_-, e instituido canónicamente por el obispo de La Imperial, Antonio de San Miguel, en 1573. El arzobispo consultaba si era posible elegir priora del monasterio a una monja que no tuviese la edad y calidad requeridas por el Concilio de Trento, ${ }^{54}$ y que aún no contara con una licencia papal para ello. ${ }^{55}$ La congregación explicaba que, en este caso, debía requerirse al pontífice el conceder facultad al ordinario para nombrar a la persona que estuviese más cercana a cumplir los requisitos del ecuménico. ${ }^{56}$

El documento de Mogrovejo y las respuestas de la Congregación representan una viva muestra de cómo la normativa eclesiástica fue construyéndose a partir de situaciones y realidades locales, como ocurrió frecuentemente en la América española en el proceso

53 Esto no parece del todo claro, porque para entonces ya se había creado un monasterio de agustinas en Santiago. Cfr. Guarda (2016, p. 234).

54 El Concilio de Trento decía que, si no se cumplían estos requisitos, se podía tomar una monja de otro monasterio que sí los cumpliera. El capítulo VII de reforma de regulares de la sesión 25, Qué personas, y de qué modo se han de elegir por abadesas o superioras bajo cualquier nombre que lo sean. Ninguna sea nombrada por superiora de dos. Cfr. López de Ayala (1857, p. 374).

55 « $\mathrm{Si}$ in uno monasterio monialium nulla sit monialis habens aetatem professionem et qualitates requisitas a sacro Concilio Tridentino ut possit esse priorissa vel abbatissa et in illa civitate vel loco nullum aliud monasterium monialium existat, prout in oppido, civitate nuncupata de Chili, an possit eligi in priorissam vel abbatissam una monialis non habens aetatem et qualitates requisitos que non tunc petatur licencia a S. ${ }^{\text {mo }}$ D. N ${ }^{\text {ro }}$ Papa» (AAV, Congr. Concilio, Positiones, vol. 108, f. 30r).

56 «Ad 27. Postulandam S.mo qui ut propterea quod monasterium est longe dissitum ut pote in Indiis benigne indulget ordinario ut proximiorem qualitatibus a Concilio Tridentino requisitis monasterio praeficiat» (AAV, Congr. Concilio, Positiones, vol. 108, f. 30r). 
de instauración de la Iglesia en esta parte del mundo. Como era común, la solución a una problemática concreta podía surgir tanto de una fuente canónica — textos canónicos, decretos tridentinos, bulas y breves papales, etc.- como de la modificación de la norma para ajustarla a contextos específicos. Por su parte, las resoluciones de la congregación del Concilio también conformaron normativas nuevas caracterizadas por su gran maleabilidad en la solución de problemáticas locales, las que a su vez podían servir de modelo para otros contextos eclesiásticos. ${ }^{57}$ De hecho, se ha considerado que las respuestas que la congregación dio a las dudas de Toribio de Mogrovejo, sentaron un precedente para los gobiernos diocesanos postridentinos en general (cfr. Rodríguez Valencia, 1956-1957, pp. 157-158, nota 34).

\section{Conclusiones}

El Concilio de Trento, al ampliar la jurisdicción de los obispos, cambiaba el panorama de poder eclesiástico en América, donde como vimos, la acción de las órdenes regulares, al menos en un comienzo había predominado sobre la de la jerarquía diocesana y del clero secular. En la provincia eclesiástica del Perú, el cambio fue introducido por el segundo y tercer concilio limense. Por supuesto, el aumento de la autoridad de facto de obispos y prelados fue resentido por otras facciones de la Iglesia americana, las que intentaron aplacarlo con diversas medidas, incluso, mediante el envío de recursos a la Santa Sede.

En la segunda mitad del siglo, a partir de la incorporación de las nuevas normativas dirigidas a todos los cuerpos institucionales presentes en América, se fueron dilucidando la jurisdicción y las

57 De hecho, podrían servir a otras diócesis que tuvieran problemas similares, aunque fueran de lugares completamente diferentes, o que incluso estuvieran en diferentes continentes. 
atribuciones de cada grupo o sector institucional. Los textos reguladores como los concilios y sínodos provinciales, las cédulas reales, los dictámenes de las audiencias y de los jueces locales, entre otros, brindaron el marco general de las diversas jurisdicciones y sus límites, aunque su margen de acción fue más flexible en la práctica.

El estudio de las comunicaciones enviadas desde el arzobispado de Lima a Roma, en la fase clave de organización de la Iglesia sudamericana, deja entrever que el gobierno metropolitano era más complejo que lo que podía establecer el Concilio de Trento. En innumerables ocasiones, el arzobispo y los obispos tuvieron que competir con otros grupos eclesiásticos — como el clero secular y los cabildos catedralicios - que habían adquirido importantes cuotas de poder en sus localidades ${ }^{58}$. Esto se hacía aún más plausible en los períodos de sede vacante, en que el deán y cabildo asumía el gobierno metropolitano o diocesano, en el caso de los obispados sufragáneos. Todo esto sin contar la constante presión ejercida por el Patronato regio, que en la práctica permitía a autoridades locales dirimir sobre cuestiones de administración eclesiástica.

En este escenario de intercambio entre América y Roma, Jerónimo de Loaysa primero, y Toribio de Mogrovejo después, buscaron fortalecer su autoridad e injerencia en el gobierno de la provincia mediante la celebración de concilios provinciales, los cuales tenían un sustento seguro en el concilio de Trento y en la Santa Sede. Las reuniones provinciales creaban un espacio ideal para establecer un diálogo con Roma, el cual fue aprovechado por los arzobispos de Lima para presentar peticiones y dudas dirigidas a

58 Una situación más bien común, derivada también de la aplicación del Patronato y la superposición de jurisdicciones entre el ámbito seglar y eclesiástico. «La legislación real que se relacionaba con las materias religiosas y eclesiásticas, creaba dificultades a los obispos. Estos estaban obligados a coordinar en la práctica esta doble legislación, con el agravante de no poder conocer las dichas cédulas, que en gran número se guardaban en los archivos de las oficinas reales. Esto originaba encuentros entre Oidores y Obispos» (Silva, 1985, p. 93). 
resguardar la autoridad y jurisdicción episcopal que en ese momento se veían amenazadas, como demuestran las fuentes revisadas. ${ }^{59}$

Finalmente, las respuestas que los arzobispos recibieron de la congregación del Concilio les brindaron seguridad para tomar control sobre sus gobiernos metropolitanos y consolidar un estilo de organización diocesana que trascendió, y que le terminó dándole a Santo Toribio de Mogrovejo la denominación pontificia de Patrono del Episcopado Latinoamericano.

\section{Archivos}

Archivo Apostólico Vaticano (AAV)

Congr. Concilio, Positiones, vol. 58, ff. 368r/v; 373r/v.

Congr. Concilio, Positiones, vol. 107, ff. 14r-15v

Congr. Concilio, Positiones, vol. 108, ff. 29r-30v; 36r-37v.

Congr. Concilio, Libri Litter., vol. 6, ff. 98r/v.

Congr. Concilio, Libri Decret., vol. 7A, ff. 46-47.

\section{REFERENCIAS}

\section{FUENTES IMPRESAS}

Benito, José Antonio (2006). Libro de visitas de Santo Toribio Mogrovejo (15931605). Introducción, transcripción y notas de José Antonio Benito. Lima: Pontificia Universidad Católica del Perú.

Grignani, Mario (2009). La regla consueta de Santo Toribio de Mogrovejo y la primera organización de la Iglesia americana. Santiago: Ediciones Universidad Católica de Chile.

59 «L'appello alla Congregazione, dunque, sembra essere spesso fatto per evitare il ricorso alle autorità local o per ottenere dichiarazioni autorevoli che permettano di far pressione sulle parti avversarie o sulle stesse istituzioni local in sede di giudizio» (Albani, 2009, p. 72). Véase la valoración que la congregación del Concilio hizo de las consultas realizadas por Mogrovejo en Martínez Ferrer (2018). 
Haroldo, Francisco de (1673). Lima Limata Conciliis, constitutionibus synodalibus et allis momumentis, quibus venerab. servus Dei Toribius Alphonsus Mogroveius archiepisc. Roma: Typis Iosephi Corvi.

León Pinelo, Antonio de (1653). Vida del Ill.mo y Rev.mo D. Toribio Alfonso de Mogrovejo Arçobispo de la ciudad de los Reyes Lima Cabeza de las Provincias del Perú. Madrid.

López de Ayala, Ignacio (1857). El sacrosanto y ecuménico Concilio de Trento. París: Librería de Rosa y Bouret.

Martínez Ferrer, Luis (ed.) y José Luis Gutitérrez (trad.) (2017 [1585]). Tercer Concilio Limense (1583-1591). Edición bilingüe de los decretos. Lima: Quad Graphics.

Recopilación de Leyes de los Reynos de las Indias, mandadas imprimir y publicar por la Magestad católica del rey Don Carlos II (1681). Tomos I-IV. Madrid: Iulian de Paredes.

Tejada y Ramiro, Juan (1859). Colección de cánones y de todos los concilios de la Igleisa de España y de América. Traducción castellana con notas e ilustraciones. Volumen IV. Madrid: Imprenta de D. Pedro Montero.

Vargas Ugarte, Rubén (1952). Concilios Limenses (1551-1772). Tomo I. Lima: Tipología Peruana.

\section{Bibliografía}

Acosta, Antonio (1996). «La Iglesia en el Perú colonial temprano. Fray Jerónimo de Loaysa, primer obispo de Lima». Revista Andina, vol. 14, núm. 1, pp. 53-71.

Albani, Benedetta (2009). «In universo christiano orbe: La Sacra Congregazione del Concilio e l'amministrazione dei sacramenti nel Nuovo Mondo (secoli XVI-XVII)». Mélanges de l'école française de Rome, vol. 121, núm. 1, pp. 63-73.

Armas Medina, Fernando (1953). Cristianización del Perú 1532-1600. Sevilla: Escuela de Estudios Hispano-Americanos de Sevilla. 
Autores Varios (2007). Toribio de Mogrovejo. Misionero, Santo y Pastor. Actas del Congreso académico internacional realizado en Lima del 24 al 28 de abril de 200. Lima: Pontificia Universidad Católica del Perú.

Azamburu-Zudaire, José Miguel (1990). «Don Sebastián de Lartaun, un obispo guipuzcoano en Cuzco (s. XVI)». En: Josep-Ignasi Saranyana, Primitivo Tineo, Antón M. Pazos, Miguel Lluch-Baixaulli y María Pilar Ferrer (eds.). Evangelización y teología en América (siglo XVI): X Simposio Internacional de Teología de la Universidad de Navarra. Navarra, Universidad de Navarra, pp. 377-393.

Barreto, Ângela e Ines Zupanov (2015). Catholic Orientalism: Portuguese Empire, Indian Knowledge: 16.-18. Centuries. Nueva Delhi: Oxford University Press.

Barrio Gozalo, Maximiliano (2010). El clero en la España moderna. Córdoba: Consejo Superior de Investigaciones Científicas.

BurriezA, Javier (2004). «Los misioneros en la monarquía». En: Teófanes Egido, Javier Burrieza y Manuel Revuelta (eds.). Los jesuitas en España y en el mundo bispánico. Madrid: Marcial Pons, pp. 179-224.

BURrieZA, Javier (2007). Jesuitas en Indias: entra la utopía y el conflicto: trabajos y misiones de la Compañia de Jesús en la América moderna. Valladolid: Universidad de Valladolid.

Cainzza, Piero (1992). Tra Stato e Papato. Concili provinciali post-tridentini (15641648). Roma: Herder.

Cobo Betancourt, Juan (2014). The reception of Tridentine Catholicism in the New Kingdom of Granada. Tesis de doctorado. Cambridge: Universidad de Cambridge.

Delgado Criado, Buenaventura (1993). Historia de la educación en España y América. Volumen 2. Madrid: Fundación Santa María y Ediciones SM.

Ditchfield, Simon (2011). «Trent Revisited». En: Adriano Prosperi (ed). La fede degli Italiani. Pisa: Edizioni della Normale, pp. 357-370. 
Ditchfield, Simon (2013). «Tridentine Catholicism». En: A. Bamji, A. y M. Laven (eds.). The Ashgate Research Companion to the Counter-Reformation. Farnham: Ashgate Publishing, pp. 15-31.

Dougnac Rodríguez, Antonio (1994). Manual de Historia del Derecho Indiano. México: Instituto de Investigaciones Jurídicas de la Universidad Nacional Autónoma de México.

Estenssoro Fuchs, Juan Carlos (2003). Del paganismo a la santidad. La incorporación de los indios del Perú al catolicismo 1532-1750. Lima: Instituto Francés de Estudios Andinos.

Fernández Terricabras, Ignasi (2000). Felipe II y el clero secular. La aplicación del Concilio de Trento. Madrid: Sociedad Estatal para la Conmemoración de los Centenarios de Felipe II y Carlos V.

García Irigoyen, Carlos (1906-1907). Santo Toribio, Obra escrita con motivo del tercer centenario de la muerte del Santo Arzobispo de Lima. Tomos I-IV. Lima: Imprenta y Librería de San Pedro.

GONZÁLEZ GONZÁLEZ, Enrique (2010). «La definición de la política eclesiástica de Felipe II (1567-1574)». En: Francisco Javier Cervantes Bello (ed.). La Iglesia en la Nueva España: Relaciones económicas e interacciones politicas. Ciudad de México: Benemérita Universidad Autónoma de Puebla, pp. 143-164.

Guarda, Gabriel (2016). La Edad Media de Chile: Historia de la Iglesia desde la fundación de Santiago a la incorporación de Chiloé 1541-1826. Santiago: Ediciones UC.

Kamen, Henry (1998). «La política religiosa de Felipe II». Anuario de Historia de la Iglesia, núm. 7, pp. 21-33.

Leturia, Pedro (1930). «El regio vicariato de Indias y los comienzos de la Congregación de Propaganda Fide». Spanische Forschungen der Görresgesellschaft, vol. II, pp.133-177.

Leturia, Pedro y Antonio de Egaña (1959). Relaciones entre la Santa Sede e Hispanoamérica, 1493-1835. Volumen 1: época del real patronato, 
1493-1800. Caracas; Roma: Sociedad Bolivariana de Venezuela; Universidad Gregoriana.

LeVILlier, Roberto (1919). Organización de la Iglesia y Órdenes religiosas en el Virreinato del Perú en el siglo XVI. Documentos del Archivo de Indias, I-II. Madrid: Sucesores de Ribadeneyra S.A.

López Lamerain, Constanza (2011a). «El Concilio de Trento y Sudamérica: Aplicaciones y adaptaciones en el III Concilio Limense». Anuario de Historia de la Iglesia en Chile, núm. 29, pp. 15-32.

López Lamerain, Constanza (2011b). «El III Concilio de Lima y la conformación de una normativa evangelizadora para la provincia eclesiástica del Perú». Intus-Legere Historia, vol. 5, núm. 2, pp. 51-68.

López Lamerain, Constanza (2018). «Translating Canon Law into Local Reality: From Trent to Santiago de Chile». En: Hugo Beuvant, Thérence Carvalho y Mathilde Lemée (eds.). Les Traductions du Discours Juridique. Perspectives Historiques. Rennes: Presses Universitaires Rennes, pp. 47-48.

Luque Alcaide, Elisa (2008). La Iglesia en América Latina (Siglos XVI-XVIII): Continuidady Renovación. Pamplona: EUNSA.

Martínez Ferrer, Luis (2001). «La documentación del Archivo Secreto Vaticano (Fondo Congr. Concilio, Concilia) sobre los concilios provinciales en Latinoamérica (s.XIX)». Hispania Sacra, núm. 53, pp. 677-693.

Martínez Ferrer, Luis (2009). «El proceso de institucionalización de la Iglesia católica en Iberoamérica (Siglos XVI-XVIII)». En: Fernando Armas Asin (ed.). La invención del catolicismo en América. Los procesos de evangelización, Siglos XVI-XVIII. Lima: Universidad Nacional Mayor de San Marcos, pp. 19-44.

Martínez Ferrer, Luis (2015). «Apelaciones al clero de Charcas al Tercer Concilio de Lima (1583-1584)». Annuarium Historiae Conciliorum, vol. 47, núm. 2, pp. 324-370. 
Martínez Ferrer, Luis (2018). «Un nuevo testimonio (inédito) de la valoración de Santo Toribio en la Santa Sede. Carta de la Sagrada Congregación del Concilio (28 Mayo 1591)». Revista Teológica Limense, vol. LII, núm. 1, pp. 99-116.

Martínez Ferrer, Luis (en prensa). «Domingo de Almeyda, procurador en Madrid y Roma del clero de Charcas (1583-1591)». Historia y Cultura. Revista de la Sociedad Bolivariana de Historia, núm. 43.

Martínez Ferrer, Luis y Carmen Alejos Grau (1999). «Las reuniones eclesiásticas anteriores a la recepción de Trento». En: JosephIgnasi Saranyana (dir.). Teología en América Latina Volumen I. Madrid: Iberoamericana, pp. 89-130.

McGlone, Mary M. (1993). «The Mission Methodology of Toribio de Mogrovejo». The Americas, vol. 50, núm. 1, pp. 65-86.

Merluzzi, Manfredi (2007). «Religion and State policies in the age of Philipp II: The 1598 Junta Magna of the Indies and the new political guidelines for the Spanish American Colonies». En: Joaquim Carvalho (ed.). Religion and power in Europe: Conflict and convergence. Pisa: Pisa University Press, pp. 183-201.

Merluzzi, Manfredi (2014). Gobernando los Andes. Francisco de Toledo virrey del Perú (1569-1581). Lima: Pontificia Universidad Católica del Perú.

Moutin, Osvaldo (2009). "Construyendo la jurisdicción episcopal en la América hispánica: La primera consulta al Tercer Concilio Provincial Mexicano (1585)». Revista de Historia del Derecho, vol. 37, pp. 1-25.

Moutin, Osvaldo (2016). Legislar en la América hispánica en la temprana edad moderna: Procesos y características de la producción de los Decretos del Tercer Concilio Provincial Mexicano (1585). Frankfurt am Main: Max Planck Institute for European Legal History.

Naz, Raoul (1953). Dictionnaire de Droit Canonoique. Tomo V. París: Libraire Letouzey et Ané. 
O'Malley, John W. (2000). Trent and all that: Renaming Catholicism in the Early Modern era. Cambridge MA: Harvard University Press.

O'Malley, John W. (2002). «The Council of Trent: Myths, misunderstandings and misinformation». En: Thomas M. Lucas (ed.). Spirit, Style, Story. Essays Honouring John W. Padberg SJ. Chicago: Loyola Press, pp. 205-226.

Ortiz Treviño, Rigoberto (2003). «El tercer Concilio Provincial Mexicano, o cómo los obispos evadieron al Real Patronato Indiano». Anuario Mexicano de Historia del Derecho, núm. 15, pp. 77-94.

Pérez Puente, Leticia (2007). «Trento en México. El Tercer Concilio Provincial Mexicano». En: Derecho, Historia y Universidades, Estudios dedicados a Mariano Peset. Volumen 2. Valencia: Universidad de Valencia, pp. 411-422.

Pérez Puente, Leticia (2017). Los cimientos de la Iglesia en la América española: Los Seminarios Conciliares, Siglo XVI. México: Universidad Nacional Autónoma de México.

Ramos Pérez, Demetrio (1986). «La crisis indiana y la Junta Magna de 1568». Jahrbüch für Geschichte von Staat, Wirtschaft und Gesellschaft Lateinamerikas, núm. 23, pp. 1-61.

Rodríguez Valencia, Vicente (1956-1957). Santo Toribio de Mogrovejo, organizador y apóstol de Sur-América I-II. Madrid: Consejo Superior de Investigaciones Científicas.

Rodríguez Valencia, Vicente (1957). El Patronato regio de Indias y la Santa Sede en Santo Toribio de Mogrovejo (1581-1606). Roma: Iglesia Nacional Española.

Romita, Fiorenzo (1964). «Le origini della S.C. del Concilio». En: La sacra congregazione del concilio. Quarto centenario della Fondazione (1564-1964). Studi e ricerche. Ciudad del Vaticano: Editorial Vaticana, pp. 13-50.

Saranyana, Josep-Ignasi y Carmen Alejos Grau (1999). «La primera recepción de Trento en América (1565-1582)». En: Josep-Ignasi Saran- 
yana (ed.). Teología en América Latina. Desde los orígenes a la Guerra de Sucesión (1493-1715). Madrid; Frankfurt am Main: Iberoamericana Verbuet, pp. 131-148.

Severo, Aparicio (1958). Influjo de Trento en los Concilios Limenses. Madrid: Raycar S.A.

SILVA, Luis Eugenio (1985). «El "Gobierno eclesiástico Pacífico y unión de los dos cuchillos, pontificio y regio" de Fray Gaspar de Villaroel, O.S.A.». Anuario de Historia de la Iglesia en Chile, vol. 3, pp. 91-100.

Terráneo, Sebastián (2015). «El oficio de juez en la Iglesia indiana». Anuario Argentino de Derecho Canónico, vol. 21, pp. 357-374.

Tineo, Primitivo (1990). Los Concilios Limenses en la evangelización Latinoamericana. Labor organizativa y pastoral del Tercer Concilio Limense. Pamplona: Ediciones Universidad de Navarra.

Tineo, Primitivo (1996). «La recepción de Trento en España (1565). Disposiciones sobre la actividad episcopal». Anuario de Historia de la Iglesia, núm. 5, pp. 241-296.

Traslosheros, Jorge (2014). Historia judicial eclesiástica de la Nueva España. Materia, método y raz̨ones. México: Editorial Porrúa.

Trujillo Mena, Valentín (1981). La legislación eclesiástica en el Virreinato del Perú durante el siglo XVI. Con especial atención a la jerarquia y a la organización diocesana. Lima: Ed. Lumen.

Tudini, Flavia (2018). «El arzobispo de Lima Jerónimo de Loayza (15431575), entre el gobierno temporal y el gobierno espiritual». En: María Ángeles Pérez Samper y José Luis Betrán Moya (eds.). Nuevas perspectivas de investigación en Historia Moderna: Economía, Sociedad, Política y Cultura en el Mundo Hispánico. Madrid: Fundación Española de Historia Moderna, pp. 898-908.

Vargas Ugarte, Rubén (1953). Historia de la Iglesia en el Perú. Tomo I. Lima: Imprenta Santa María. 
Vargas Ugarte, Rubén (1959). Historia de la Iglesia en el Perú. Tomo II (15701640). Burgos: Imprenta de Aldecoa.

Vargas Ugarte, Rubén (1965). Historia de la Compañia de Jesús en el Perú. Burgos: Imprenta de Aldecoa.

Villegas, Juan (1975). Aplicación del Concilio de Trento en Hispanoamérica 1564-1600, Provincia Eclesiástica del Perú. Cuadernos Del Itu 3. Montevideo: Instituto Teológico del Uruguay.

Vizuete MendozA, Juan Carlos (2014). «La Iglesia Peruana después de Trento». En: Francisco Javier Campos y Fernández de Sevilla (ed.). El Perú en la época de Felipe II. San Lorenzo del Escorial: Instituto Escurialense de Investigaciones Históricas y Artísticas, pp. 157-184.

\section{Agradecimientos}

La investigación que hizo posible la realización de este artículo fue financiada por el proyecto de investigación «Governance of the Universal Church after the Council of Trent. Papal Administrative Concepts and Practices as exemplified by the Congregation of the Council between the Early Modern Period and the Present», llevado a cabo en el Max Planck Institute for Legal History and Legal Theory de Frankfurt (Alemania). Brindo mis sinceros agradecimientos al Dr. Renzo Honores por invitarme a ser parte de este dossier, y al Dr. Andrea Cicerchia por su colaboración en la transcripción y traducción de los documentos romanos aquí citados. Agradezco también a los evaluadores pares ciegos quienes con sus pertinentes correcciones enriquecieron el contenido de este artículo.

Fecha de recepción: 9 de febrero de 2021. Fecha de evaluación: 22 de marzo de 2021. Fecha de aceptación: 21 de mayo de 2021. Fecha de publicación: 30 de junio de 2021. 